\title{
GABRIEL MIRO Y LA INDIVIDUALIDAD ENDOCRINA
}

\section{Kevin S. Larsen}

Reconocer al Miró estilista de primer orden no implica el negarle su interés intelectual, ni viceversa, ya que su literatura se ha edificado sobre un armazón construido de materiales apropiados tanto de belles lettres como de otras muchas disciplinas. Una de éstas es la ciencia: quizá la mayor parte de la inspiración del novelista alicantino venga «del sabio libro de la Naturaleza" (1), pero no cabe duda que muchos libros sobre diversos temas de investigación, desde la biología de Darwin y Lamarck hasta la psicología de Binet y Ribot y la física de Lucrecio y Gustave Le Bon, también han dejado su huella permanente en su obra narrativa (2). A este nivel científico, también hay que señalar la importancia de la medicina y los médicos en la obra de Miró. Leía extensivamente en ciertos campos médicos y conocía a varios médicos contemporáneos suyos, quienes influían bastante en su entendimiento de su disciplina.

Además, ya han notado muchos escritores el papel señalado de la enfermedad, especialmente la lepra, en la ficción de Miró (3). Muchas veces el médico ejerce su arte sanador (o al menos confortador), tal como don Hermenegildo Poquet de Del vivir (1904) y don Vicente Grifol de Nuestro Padre San Daniel (1921) y El obispo leproso (1926), y así llega a ser una bendición para los pacientes (4). Pero a veces la medicina 
amenaza a la humanidad al querer hacerle un «bien». Tal caso se encuentra en «Razón y virtudes de muertos» (1914), ahora incluido en $\mathrm{Li}$ bro de Sigüenza. Es una antigua cuestión platónica que trata Miró, mientras su alter ego Sigüenza explora las relaciones entre el individuo y su "sentimiento de sí mismo y el grupo». Mira "su carne» y "la carne de los demás» y piensa en cuántas células tienen los cuerpos (" $i$ Treinta trillones o sesenta trillones? Es igual»). Prefiere, en fin, considerar la "unidad, como hombre», en vez de «la vida esparcida... como pensaría el biólogo» (pp. 641-42). A pesar de lo que Miró crea, un buen biólogo también reconocería que la suma del hombre es más que un conjunto de células. Tal como el autor, la biología se da cuenta de que una persona es un individuo, al igual que cualquier parte de su cuerpo tiene su individualidad, pero la comunidad y la cooperación literalmente le animan, en un sentido "microscópico», si no en uno «macroscópico».

Por eso, Sigüenza, el «hombre apartadizo» (5) que pasa tanto tiempo en el campo reconfirmando sus conexiones con la comunidad natural, también quiere afirmar su propia unidad en la multiplicidad. Meditando estas cuestiones del individuo en cuanto a entidad y en cuanto a grupo, el protagonista peripatético encuentra «la estupenda noticia de que un médico de Chicago confía haber hallado el remedio de la locura injertando en los pobres locos ciertas glándulas arrancadas de los cadáveres. Estas glándulas segregan el divino licor de la razón que beben ávidamente las células nerviosas del cerebro. El sabio fisiólogo ha ensayado su descubrimiento en dos mujeres. Todavía se desconoce su eficacia » (p. 642). No es ésta la primera vez en su corpus literario que Miró haya aludido a la modificación del cuerpo: en Las cerezas del cementerio (1910), el bárbaro Álonso intentó injertar tejidos de un pollo en otro, produciendo un verdadero monstruo que pronto murió (6). Hay ciertas diferencias importantes entre los dos casos, aunque ambos traten de la mentalidad "frankensteiniana", donde los intentos de "cambiar» la naturaleza resultan ambiguos, si no obviamente desastrosos. Aún más similar a la situación descrita en «Razón y virtudes de muertos» es lo que pasa en Le docteur Pascal (1893), donde el médico epónimo hace una serie de experimentos con las inyecciones, descubriendo que las más eficaces son las de agua pura. Pero Miró, aunque siempre tenga presente la obra de Zola, va mucho más allá de esta sola fuente (7). Es muy posible que él y su Sigüenza hayan leído algo en una revista sobre tal experimento en los Estados Unidos -en un período eran relativamente comunes tales inyecciones experimentales allí, tanto como 
en Europa- y que hubiera un médico de Chicago tal como describe. Puede que éste fuera el Dr. Shobal Vail Clevenger, Jr., llamado por un biógrafo «The Don Quixote of Psychiatry», quien contribuyó unos importantes estudios endocrinológicos y también llegó a ser director del Illinois Eastern Hospital for the Insane (8). Sea o no dicho doctor, lo más importante es la manera en que Miró utilice lo que sabe de tales inyecciones y cómo se relaciona su obra con la de otros que han escrito sobre el mismo tema.

Antes de Miró, hubo una larga tradición de investigaciones sobre las posibles modificaciones del comportamiento humano efectuadas por inyecciones de varias sustancias. Aunque no inyectadas, se había creído con asiduidad durante la Edad Media y aún después en las virtudes milagrosamente terapéuticas de sueros destilados de los cadáveres de santos y santas (9). Ya después de siglos y revoluciones bacteriológicas y farmacológicas, todavía se puede notar cierto elemento de esta esperanza taumatúrgica en las investigaciones de algunos científicos de la época «moderna». En la década de 1850, por ejemplo, Claude Bernard, la inspiración médica de la novela experimental de Zola y un nombre bastante familiar a Miró, se había interesado profundamente en el papel de las secreciones in ternas en los procesos corporales. Mientras tanto, su sucesor en la Universidad de París, Charles BrownSéquard, explicó en 1889 que las inyecciones de hormonas de ranas y perros tenían cierto efecto rejuvenecedor en el hombre. Otro científico, el alemán Eugen Steinach, hacía intervenciones quirúrgicas en las cuales trasladaba extractos de los testículos de animales o se los injertó al hombre directamente para estimular un rejuvenecimiento viril. Este tratamiento alcanzó su más alta popularidad en la década de 1920. Además, se usaba una droga, "Cerebrine Alpha», para tratar a la neurastenia: "As dangerous as this treatment really was, if a doctor accepted the premise that neurasthenics were lacking in nerve strength because of civilization, it wouldn't be difficult... to arrive at the idea that a good shot of strong nerve tissue from an uncivilized animal might turn the nervous human being around " (10). Se nota aquí cierto recuerdo o residuo de la doctrina de Nietzsche acerca del hombre civilizado como un animal enfermo y la civilización como su enfermedad. Además, se anticipa a Freud, con sus ideas sobre la "Civilización y sus descontentos», aunque el psicoanalista austriaco vaya más allá de una respuesta química, impuesta (o inyectada) desde afuera, a los problemas psicológicos. Por otra parte, es de interés recordar en este contexto que aún hoy en día la gente (adinerada, por supuesto) que desea «rejuvene- 
cerse» puede inscribirse en ciertas clínicas de Suiza para recibir este tipo de inyecciones, éstas de tejido triturado de embriones ovejunos.

En España también se experimentaba con tal tipo de modificaciones psicofísicas de la química humana. Por ejemplo, Mariano RuizFunes dice que «la endocrinología es una fuerza más que coopera a la labor de transformar tristes residuos humanos en útiles energías, aptas para el trabajo y para la obra de la civilización y de la cultura». Discute la inyección de materia testicular, igual que su injerto directo en el cuerpo humano, según la práctica de un italiano, Mario Carrara (11). Además, Ruiz-Funes menciona a Gregorio Marañón, amigo de Miró, como bien se sabe, muy entregado a cuestiones de endocrinología y sus posibles modificaciones. Un libro suyo, La doctrina de las secreciones internas (1915), que formaba parte de la colección personal de Miró, evidencia su mutuo acercamiento en cuanto a este tema. También figura en esta colección particular Los mecanismos de correlación fisiológica, adaptación interna y unificación de funciones, otro libro que trata de aspectos de esta misma materia, escrito por otro amigo de Miró, Augusto Pi Suñer. Este doctor habla del «formidable progreso de la Endocrinología, tan pródiga en aplicaciones clínicas» y de «la mutua influencia de los plasmas que conviven, con sus peculiares condiciones físico-quimicas, tan importantes en la integración funcional de la vida celular». Luego, concluye, recordando lo que escribe Miró en «Razón y virtudes de muertos», que «el individuo en cualquiera de sus manifestaciones, tanto fisiológicas como psíquicas, se define por la estrecha unidad -química y nerviosa- de que es asiento» (12).

Incluso «nuestro sabio Ramón y Cajal », como llama Miró al famoso histólogo (13), trataría del tema de las inyecciones y sus provechos, verdaderos o irónicos. Si Miró conociera los cuentos «A secreto agravio, secreta venganza» $\mathrm{y}$ "El fabricante de honradez», publicados en Cuentos de vacaciones (1905), le habrían sido de mucho interés y actualidad, tanto en un nivel literario como en uno más científico (14). En ellos el doctor Cajal examina las modificaciones psicofísicas causadas por ciertos sueros destilados de la piel y ciertos órganos internos de animales viejos. A diferencia de la gran mayoría de los médicos que querían rejuvenecer a la gente, el doctor Forschung descubre lo que llama la "senilina» para hacer envejecer, aunque sólo exteriormente, a su ya arrepentida esposa adúltera, para protegerla, igual que a sí mismo, de otras posibles tentaciones. Encuentra un mercado casi inagotable para esta droga y va a enriquecerse sobremanera. Pero el narrador, así como Miró haría más tarde en «Razón y virtudes de muertos», va 
al grano en cuanto a la posibilidad de la vacunación universal: "i"Senilinas." a nosotros... en cuyos cartilagineos cerebros existen ya en proporciones desconsoladoras tantas "misticinas", "decadentinas" y "misoneinas", triste legado de edades bárbaras y de una pereza mental de cinco siglos!» (15). Luego, en «El fabricante de honradez», el doctor Mirahonda descubre un suero que "goza de la singular propiedad de moderar la actividad de los centros nerviosos donde residen las pasiones antisociales» y que «al mismo tiempo exalta y vivifica las imágenes de la virtud» (16). Se impone la vacuna a la sociedad, que se ve radicalmente modificada, pero al final, se para el tratamiento y hay una contrarreacción donde se surten todas las pasiones negativas antes reprimidas. En este cuento, tal como en "A secreto agravio, secreta venganza», Cajal, por boca de Mirahonda, afirma ciertas conclusiones irónicas, aunque biológicamente verdaderas, en cuanto a la "ortopedia mental» (17). Vale decir que sin el mal, no hay progreso y evolución: se suprime y luego se pierde la individualidad, y con ella, el esfuerzo hacia algo diferente y posiblemente mejor (18).

Es esta amenaza al individuo la que más preocupa a Miró en cuanto al experimento del médico de Chicago, temiendo en él «la levadura de un peligro para la propia personalidad». Se pregunta Sigüenza: « ¿Sanarán los cerebros de las dos mujeres locas con ese injerto de razón, de luz?». Luego se contesta "como esotérico del culto de las ciencias médicas, como profano de esas disciplinas del saber... que sí, que es posible que se curen». Pero reconoce que «precisamente por no estar iniciado, ha podido contestarse todo lo contrario y sonreír de la audacia del médico de Chicago». En otras palabras, duda, tal como Cajal había dudado antes, de la sabiduría de tales tratamientos:

La esperanza y la inquietud han conturbado su ánimo, porque si ese injerto redime al loco, ¿no se habrá iniciado la posible posesión de la gracia y de la salud éticas por medios fisiológicos? ¿No puede llegar un día maravillosamente clínico en que se cultiven y se injerten las sustancias y glándulas de los cadáveres de hombres virtuosos, prudentes y heroicos? Y no puede Sigüenza compadecerse de los esforzados, de los santos y de los sabios que fueron... a costa de recios sacrificios, cuando las gentes de mañana pueden igualarles y aventajarles con inyecciones de virtud, de fortaleza y de ingenio (p. 643).

Es palpable aquí lo que Miró llama en Sigüenza «la inquietud, la queja de su conciencia, del asustado sentimiento de sí mismo». El pro- 
tagonista verdaderamente «tiembla imaginando los futuros esplendores científicos» del «brave new world» ahora al horizonte. Piensa, entonces, que

La herencia fisiológica, el medio social, el trabajoso pulir nuestro interior, nuestra voluntad, nos acercan al bien y semejanza de los grandes corazones y entendimientos. Pero... admirándoles, ¿consentiríamos en trocarnos por ellos, disolvernos en ellos, como anhelaba el místico fundirse en Dios? Una pasión violenta hinca en el amante el encendido deseo de ser como lo amado, de vivir dentro de su sangre, de sus nervios, de su aliento; de vivir, de fundirse en su misma vida, pero con la ciega protesta de ser al mismo tiempo quien es, de no perderse del todo... De modo que ni por ansias de sabiduría, de belleza, de virtud ni de amor renunciamos a nosotros (pp. 643-44).

Es la misma cuestión que más tarde confrontaría Sigüenza en su meditación en la última tentación de San Antonio (Años y leguas, 1928), y merece la misma respuesta. El santo de Flaubert quería «encogerse bajo todas las formas: ser la materia». Pero el alter ego de Miró prefiere sus propias "capacidades y limitaciones como hombre», eso es, «el goce dolorido del propio contorno en la inmensidad» (19). Luego, en $\mathrm{Li}$ bro de Sigüenza, el protagonista sigue meditando, y al fin reduce la posibilidad ad absurdum:

... le queda tiempo a Sigüenza para descubrir si en la frase «Yo no me cambio por nadie" palpita un legítimo egoismo, o una pobre vanagloria, o una conciencia, legado de muchas conciencias ancestrales. Y con estos pensamientos se aparta de haber vivido en siglos futuros, en los que, no hallándole muy cabal de sosegadas virtudes, le aplicasen una "vacuna", un injerto de glándula de bondad de un varón muy bueno, muy siervo de Dios, pero que fuese un entusiasta secretario de Ayuntamiento, enamorado del Alcubilla o coleccionista de sellos... (pp. 643-44).

Este afilado escepticismo de Miró, una función de su obvio deseo personal de no perderse - como artista y como hombre-del todo en las «masas», sean químicas, estéticas o aun políticas, va mucho más allá de cualquier "vanagloria» egoista. Puede ser otra manifestación del entusiasmo desilusionado en cuanto a los beneficios de la ciencia que tanto caracterizaba el fin de siglo. Durante el siglo anterior, la ciencia, especialmente la medicina, se había proclamado como una panacea, 
pero para la época de Miró, mucha gente ya se había dado cuenta de que la utopía prometida no era necesariamente utópica. Como señala Frank Manuel en su ensayo sobre las metamorfosis del científico en las utopías, ha habido varios teorizantes modernos, desde Condorcet y Comte hasta J. D. Bernal (autor de The World, the Flesh and the Devil, 1929) y Teilhard de Chardin, quienes trataban de la submersión de la conciencia individual en la universal (20). Queda patente el rechazo irónico por Miró de tal tierra de promisión donde el individuo se pierde en la colectividad. Del mismo modo, el autor alicantino también anticipa la novela de Huxley, Brave New World (1932), donde la gente se controla $a b$ utero mediante "inyecciones» de alcohol en su sangre artificial. El ensueño de Sigüenza ya se ha hecho una verdadera pesadilla. Además, la meditación de Sigüenza es todavía un tema actual, ya que se ha surtido un debate intensivo en cuanto a los posibles usos de la somatropina, la hormona humana del desarrollo, que se recoge gota a gota de las glándulas de los cadáveres. Esta sustancia proporciona grandes beneficios, especialmente para los niños que no pueden crecer normalmente por falta de ella, y que por tal motivo se les inyecta. Pero también hay muchas preguntas éticas y prácticas, por ejemplo, la posibilidad de modificar a personas "normales», quizá para crear un super-atleta. A la luz de esta tradición siempre relevante en que participa "Razón y virtudes de muertos», no parece tener razón Ricardo López Landeira cuando asevera que «el escrito no es de índole racional, sino sentimental e imaginativa. La expresión de Miró es de sentimientos y no de ideas» (21). Para Miró los sentimientos tienen mucha importancia, pero también son centrales las ideas, sin las cuales los ideales del autor no tendrían tanto significado.

Otro científico a quien cita Miró en "Razón y virtudes de muertos» es Albert Dastre, "profesor de Fisiología de la Sorbona", cuyo libro La vie et la mort (1903), en una versión española, figura en su biblioteca personal. Sigüenza va meditando el vasto conjunto de células que forma la unidad que es el hombre, y si «esas glándulas, halladas por el sabio de Chicago... pueden verdaderamente estar aún vivas». Luego, nota que Dastre

ha dicho que «un organismo vivo no puede ser al mismo tiempo un cementerio"; que la muerte se difunde; que "es un fenómeno progresivo que comienza en un punto y se extiende al resto del hombre». Pero Dastre también ha dicho que «la muerte tiene un principio y un fin»; que, después del certificado de defunción, las uñas y los cabellos 
del muerto siguen creciendo, porque ese certificado «es un pronóstico de que el sujeto morirá», no de que esté ya muerto; "que no hay muerte verdadera sino cuando la muerte universal de todos los elementos que componen el individuo se ha cumplido". Cita el caso del fisiólogo ruso Kuliabko, que hizo latir isócronamente el corazón de un hombre dieciocho horas después del fallecimiento oficial (pp. 642-43).

Todas las citas de Miró vienen de dos capítulos del quinto libro del tomo de Dastre, llamados, respectivamente, "Proceso de la muerte» (cap. 2) y "Caracteres físicos y químicos de la muerte celular. Necrobiosis. Vejez» (cap. 3). Está claro que el autor alicantino queda muy impresionado por lo que dice el francés, citándole bastante exacta y extensivamente, sin quitar ni añadir nada que cambiara el sentido de lo que dice. Pero hay ciertas diferencias entre las citas de Miró y el texto en su biblioteca que indican o que no le preocupaban inexactitudes muy menores o que quizá consultaba una versión en francés del libro. Por ejemplo, Miró dice «no hay muerte verdadera sino cuando la muerte universal de todos los elementos que componen el individuo se ha cumplido» (p. 643), mientras la traducción española es así: «no hay muerte verdadera, más que cuando la muerte universal de todos los elementos se ha consumado» (22). Por otra parte, el francés de Dastre: «Il n'y a de mort véritable que lorsque la mort universelle de tous les éléments est consommée» (23). Quizá estos cambios, aunque insignificantes, sean una función de la ya anotada falta de completa precisión de Miró al citar, pero es más importante el sentido de lo que se dice que decir «consumado» en vez de "cumplido».

Además, se verá que estas citas, aunque den crédito a Dastre, ya pertenecen a Miró, no sólo por haberlas integrado a «Razón y virtudes de muertos", sino también porque expresan y dan apoyo intelectual a un tema que le iba a preocupar a Miró a lo largo de su carrera. Por ejemplo, varios incidentes en La novela de mi amigo (1908) se interpretan a una nueva luz en el contexto de la posible influencia de Dastre. La idea de morir del todo a una sola vez se incorpora en la frase de Federico, quien, después de imaginarse «un cadáver que tuviera un pedazo vivo de su cuerpo", parece contradecir las palabras de Dastre: «en mí se ofrece lo opuesto. Yo no estoy completamente vivo... Yo soy un cuerpo vivo que tiene muerto un pedazo de su carne. Y como lo que está muerto no puede sentir ni asistir a nada... siendo el caso contrario, inverso de aquella monstruosidad, se produce en mí igual efecto. Mi cuerpo con vida sufre constantemente el terror a un trozo de muerte. Tengo 
cuarenta y dos años, y he comenzado a morirme a los treinta y uno" (24). Sin embargo, esto no se opone al proceso de Dastre, ya que la muerte va ocurriendo pedazo por pedazo y no del todo, al menos hasta que Federico se suicida, ahogándose.

El caso de Federico muriéndose por milímetros recuerda la muerte de su padre y anticipa el fenecer de su hija moribunda. El padre iba agonizando espiritualmente, pedazo por pedazo, después de la muerte de su hija Lucita. Se le cae «encima de sus pies toda una viga, y quedó inútil y postrado; la hinchazón le subía hasta los muslos... iba gangrenándole el pie izquierdo. Se lo amputaron, y luego se le pudrió la pierna y fueron cercenándole carne a carne... Y murió... y se lo llevaron pronto porque hedía irresistiblemente» (pp. 137-38). Tal como su hijo, el padre es "cuerpo vivo que tiene muerto un pedazo de su carne», muriendo y pudriéndose lenta pero irremediablemente. Pero cuando por fin muere, hiede como un cadáver total: el proceso sucedió tal como lo explicó Dastre, aunque su mayor parte antes del «fallecimiento oficial». De igual manera, la lenta muerte de la hija de Federico sigue el modelo de Dastre, ya que lleva un proceso largo y agónico, pero cuando por fin muere, verdaderamente está muerta, al menos según la percepción del padre distraído: «dio un cortísimo suspiro. Y el padre enmudeció, transido, espantoso, porque se le había caído en los brazos toda, toda la hija muerta» (p. 153). Ha penado por tanto tiempo que no le queda nada vivo.

En otras obras de Miró se encuentra esta misma visión de lo lento y largo de proceso necrótico. En Del vivir hasta El obispo leproso la lepra llega a ser un emblema de esta descomposición, del cuerpo que se deshace pedazo por pedazo, aunque esté técnicamente vivo el sujeto. Puede que todas estas instancias representen la influencia más o menos directa de Dastre, pero también es probable que el autor alicantino esté consciente de una tradición de muchos autores contemporáneos, tanto científicos como laicos, que escribían sobre el tema de la muerte micro y macroscópica. Por ejemplo, el Dr. A. Pascual y Devesa, también de Alicante, asevera que «la muerte práctica del hombre... es anterior a la de sus tejidos. Es decir, que el individuo aparentemente se extingue ya cuando aún persiste la vida de su intimidad histológica» (25). Un poco más tarde, el Dr. R. Novoa Santos discurriría el mismo tema, enfocando la inmortalidad y la muerte en sus aspectos unitarios y celulares. Sin mencionar a Dastre por nombre, aunque hable de un investigador ruso, «un tal Krawkow» (¿Kuliabko?), quien demostró que «es posible conservar vivos durante meses fragmentos orgánicos», afirma que "a la muerte del "conjunto" organizado, a la 
anulación de la organización como totalidad, sigue la muerte de las partes que lo integran" (26). Además, hubieran interesado a Miró otras ideas de Novoa Santos, incluyendo su concepto de la inmortalidad del cuerpo por medio de sus células gérmenes, donde prevalece el individuo encima de la unidad inmediata para restablecer y mantenerla, al menos en una forma algo parecida.

Esta relación también recuerda la termodinámica biológica de algunas novelas de Miró, donde la materia y la energía se intercambian a través de las generaciones incidentales, compenetrándose en una danza de la muerte que se hace danza de la vida (27). Entonces, aunque el individuo en cierto sentido se pierda, no desaparece en cuanto a su esencia. Por otra parte, Pascual y Devesa alude a este ciclo eterno, igual que a ciertas cuestiones endocrinológicas, citando por ejemplo a BrownSéquard en cuanto a las secreciones y sus poderes de prolongar o modificar la vida (28). A su vez, Dastre trata de lo que llama la «doctrina unitaria» de la materia y la energía, escribiendo también sobre la «ley de la conservación de la materia» donde "nada se pierde; nada se crea; todo se transforma» (29). Es lógico preguntarse si La vida y la muerte no ha servido a Miró al menos para reforzar el pensamiento lucreciano desarrollado desde Las cerezas del cementerio hasta el final de su carrera. Este libro, tal como muchísimos otros sobre temas científicos, le eran para Miró como inyecciones de ideas y temas que seguirían enriqueciendo su propia obra, aunque, tal como Sigüenza, nunca entregó su independencia e individualidad crítica, un siempre «legítimo egoismo».

\section{NOTAS}

(1) Véase «Plática que tuvo Sigüenza con un capellán» (1909), ahora incluido en $L i$ bro de Sigüenza (1917), donde se discute, siempre con gran ironía, este tema de Fray Luis de Granada. MIRO, G. (1969), Obras completas, Madrid, pp. 633-35. Las demás referencias a esta novela serán anotadas, según esta edición, en el ensayo.

(2) Sobre la presencia de estos autores y sus libros en la ficción mironiana, véanse, por ejemplo, Macdonald, I. (1975), Gabriel Miró: His Private Library and His Literary Background, Londres, pp. 66-68 et passim; Márouez-VILlanUeVA, F. (1982), "La esfinge mironiana", en Harvard University Conference in Honor of Gabriel Miró, Lexington, KY, 11-34; pp. 15-17; LARSEN, K. (1986): "La ciencia aplicada": Gabriel Miró, Alfred Binet y el fetichismo", Bulletin Hispanique, 88, pp. 121-44; LARSEN, K. (1989). "Gabriel Miró, Lucretius, and Thermodynamics", Ometeca, 1, pp. 77-91.

(3) Véanse, por ejemplo, DE LA VEGA, J. (1974): La enfermedad en la obra de Gabriel Miró, Alicante y Murcia, pp. 11-17 et passim; Macdonald, I (1982), «Why is Miró's Bishop

Asclepio-I-1990 
a Leper?, Anales de la Literatura Española Contemporánea, 7, pp. 59-77; LARSEN, K. (1984), " "A la manera del teatro ibseniano": Gabriel Miró and Henrik Ibsen», Symposium, 38 pp. 43-55; Marouéz-Villanueva, F. (1990), "Las tres lepras de El obispo leproso», en La esfinge mironiana y otros estudios sobre Gabriel Miró, Alicante, pp. 97-128.

(4) Sobre la figura de don Hermenegildo, véanse MárouEZ-VillanUEVA (1990), p. 101, y SAN Martín Bacaicoa, I. (1966): La lepra en la España del siglo XIX, Valencia, p. 5. Sobre don Vicente, véase COOPE, M. (1987): "La insignificancia de don Vicente Grifol y la teoría novelística de Gabriel Miró», Revista Canadiense de Estudios Hispánicos, 12, pp. 17-31.

(5) MIRÓ, G. (1969): "Del vivir», en Obras completas, Madrid, p. 3.

(6) MIRÓ, G. (1969): "Las cerezas del cementerio», en Obras completas, Madrid, p. 367.

(7) Márquez-Villanueva, F. (1972): "Sobre fuentes y estructura de "Las cerezas del cementerio" ", en Homenaje a Casalduero, Madrid, pp. 371-77, señala varios paralelos entre Le docteur Pascal, Las cerezas del cementerio e Hilván de escenas (1903), libro temprano que Miró decidió no incluir en sus obras completas.

(8) Véanse Robinson, V. (1919), The Don Quixote of Psychiatry, Nueva York, y SuLloway, F. (1979): Freud, Biologist of the Mind, Nueva York, pp. 291-94.

(9) Véase CAMPORESI, P. (1988), The Incorruptible Flesh, Cambridge y Nueva York, pp. 3-24.

(10) DrinkA, G. (1984), The Birth of Neurosis, Nueva York, pp. 228-29. Cf. KERN, S. (1975), Anatomy and Destiny, Nueva York y Indianapolis, pp. 128-29.

(11) RuIz-FunEs, M. (1927), La criminalidad y las secreciones internas, Murcia, pp. 134-35 y 152 .

(12) PI SUÑER, A. (1920), Los mecanismos de la correlación fisiológica, adaptación interna y unificación de funciones, Barcelona, pp. 15-16 y 244.

(13) Miro, G. (1952), Glosas de Sigüenza, Buenos Aires y México, p. 136.

(14) O'CONNOR, D. (1985), «Science, Literature and Self-Censorship: Ramón y Cajal’s Cuentos de vacaciones", en Ideologies and Literature, 1, pp. 99-122, asevera que el Dr. Cajal sólo permitió una distribución muy limitada de este libro, creyendo que su contenido ideológico quizá perjudicara o comprometiera sus empresas más exclusivamente científicas. Mientras tanto, Tzitsikas, H. (1965), Santiago Ramón y Cajal: Obra literaria, México, pp. 29-74, y BENITTEz, R. (1981), "La novela científica en España: Ramón y Cajal y el Conde de Gimeno", en Studia Hispanica 1. In Honor of Rodolfo Cardona, Madrid, Austin, pp. 79-95, estudian los niveles científicos e imaginativos de los relatos. A su vez, mi colega y amigo Mellizo, C. (1989), "De Cajal a Martín-Santos», España Contemporánea, 2, 61-74; p. 69, ha escrito que «estas novelas cajalianas son hoy, en lo que se refiere a su hechura literaria, de escasa actualidad», lo que debe ser verdad, aunque en la época de Miró no lo era, ni mucho menos.

(15) RAMÓN Y CAJAL, S. (1947), "A secreto agravio, secreta venganza», en Obras literarias completas, Madrid, p. 714.

(16) RAMÓN Y CAJAL, S. (1947), "El fabricante de honradez», en Obras literarias completas, Madrid, p. 720.

(17) Ibid., p. 743. Cf. este pasaje en sus Charlas de café, también en Obras literarias completas, p. 1.270:

Es preciso ir todavía más lejos. ¿Qué obstáculos nos detienen para injertar glándulas humanas en monos? El Oriente, con sus fabricantes de eunucos, y Roma, con sus devotos laboratorios de tenores, nos ofrecerían, al efecto, material fresco abundante, sin contar con los jóvenes europeos que, por amor a la ciencia, se prestarían al cruento sacrificio.

Asclepio-I-1990 
¡Qué diablo!... Esta reciprocidad de trato bien la merecen el abnegado y sumiso chimpancé o el cinocéfalo, a quien tantas veces hemos inoculado la sífilis y otras infecciones. ¡Quién sabe si resultaría, a la postre, después de varias generaciones injertadas y remontadas intelectualmente, una raza de monos parlantes no muy inferior a la casta de parlamentarios sonoros... de las naciones constitucionales!

(18) Iriarte, J. (1958), Pensares y pensadores, Madrid, p. 57, escribe: «El mal... lejos de ser castigo, es la condición indispensable para el impulso del progreso dicho. Nosotros decimos que el mal... puede servir... de acicate de perfección; para Cajal, que considera la evolución en sus fases primeras..., es la expresión misma de esa inferioridad, y sería una contradicción concebirla exenta de mal».

(19) MIRO, G. (1969), «Años y leguas», en Obras completas, Madrid, p. 1.105.

(20) Manuel, F. (1986), "Metamorphoses of the Scientist in Utopia», en The Prism of Science, Dordrecht y Boston, pp. 11-14.

(21) LOPEZ Landeira, R. (1972), Gabriel Miró: Trilogía de Sigüenza, Madrid, p. 103.

(22) Dastre, A. (1906), La vida y la muerte, Madrid, p. 296.

(23) Dastre, A. (1911), La vie et la mort, París, p. 311.

(24) Miró, G. (1969), "La novela de mi amigo», en Obras completas, Madrid, p. 130.

(25) Pascual y Devesa, A. (1927), "La supervivencia en su aspecto médico», Revista de Estudios Metapsíquicos, 3, 1-13; p. 2.

(26) Novoa Santos, R. (1931), La inmortalidad y los orígenes del sexo, Madrid, pp. $125-26$

(27) Véase LARSEN (1989), pp. 77-91.

(28) Pascual y Devesa (1927), pp. 7-8.

(29) Dastre (1906), pp. 34-41, 63-64 y 85-87. 